\title{
Effect of electrolytes as adjuvants in GFP and LPS partitioning on aqueous two-phase systems: 1 . Polymer-polymer systems
}

\author{
André Moreni Lopes ${ }^{\mathrm{a}, *}$, João Vitor Dutra Molino ${ }^{\mathrm{b}}$, Valéria Carvalho dos Santos-Ebinuma ${ }^{\mathrm{a}}$, \\ Adalberto Pessoa Jr. ${ }^{c}$, Sandro Roberto Valentini ${ }^{\mathrm{a}}$, Jorge Fernando Brandão Pereira ${ }^{a}$ \\ a Department of Bioprocesses and Biotechnology, School of Pharmaceutical Sciences, São Paulo State University - FCFar/UNESP, Brazil \\ ${ }^{\mathrm{b}}$ Ronin Institute, Montclair, NJ, USA \\ ${ }^{\mathrm{c}}$ Department of Biochemical and Pharmaceutical Technology, School of Pharmaceutical Sciences, University of São Paulo - FCF/USP, Brazil
}

\section{A R T I C L E I N F O}

\section{Keywords:}

Green fluorescent protein (GFP)

Lipopolysaccharide endotoxins (LPS) removal

Aqueous two-phase systems (ATPS)

Poly(ethylene glycol) (PEG)

Poly(acrylic acid) (NaPA)

Inorganic salts

\begin{abstract}
A B S T R A C T
The production of recombinant biopharmaceuticals is highly dependent of a proper choice of the downstream processing stages. Particularly, the purification that must ensure that all the endotoxins (lipopolysaccharides LPS) are efficiently removed from the final product. The efficient removal of LPS has a direct impact on the manufacturing of therapeutic biopharmaceuticals, since LPS is naturally presented in Gram-negative bacterial expression systems. In order to provide a more simple and faster technique for the purification of green fluorescent protein (GFP) and LPS removal, aqueous two-phase systems (ATPS) composed of polyethylene glycol (PEG) and poly(acrylic acid) (NaPA) and electrolytes were studied. Firstly, the binodal curves of PEG/ $\mathrm{NaPA}+$ salt systems were established using $\mathrm{NaCl}, \mathrm{Li}_{2} \mathrm{SO}_{4}, \mathrm{KI}$, and $\mathrm{KNO}_{3}$ as additives. It was demonstrated that the formation of ATPS is enhanced following the anion tendency: $\mathrm{SO}_{4}{ }^{2-}>\mathrm{Cl}^{-} \gg \mathrm{NO}_{3}{ }^{-}>\mathrm{I}^{-}$. The stability of GFP in the presence of all different phase forming agents (polymers and salts) was evaluated, and the high biocompatibility of these ATPS demonstrated by the maintenance of GFP fluorescence in all conditions under study. Then, the GFP extraction and LPS removal aptitude of each ATPS was investigated. GFP and LPS were preferentially partitioned into the top (PEG-rich) phase $\left(K_{\mathrm{GFP}}>20\right)$, but with a removal of $35 \%$ of LPS was attained. Hydrophobic and electrostatic interactions were found to be the major driving forces for GFP partitioning and LPS removal. Moreover, a new effect was found, the presence of high loads of LPS can affect (decrease) the $K_{\mathrm{GFP}}$ values ( $K_{\mathrm{GFP}}$ without LPS $>K_{\mathrm{GFP}}$ with $10^{4} \mathrm{EU} / \mathrm{mL}>K_{\mathrm{GFP}}$ with $10^{6} \mathrm{EU} / \mathrm{mL}$ ). The ATPS with best GFP extraction performance was selected for the recovery directly from the cell lysates of Escherichia coli. In this experiment, the system composed of $12 \mathrm{wt} \%$ PEG $1000 \mathrm{~g} / \mathrm{mol}, 12 \mathrm{wt} \% \mathrm{NaPA} 8000 \mathrm{~g} / \mathrm{mol}$, and $0.25 \mathrm{M} \mathrm{Li}_{2} \mathrm{SO}_{4}$ lead to a LPS removal ( $R E M_{\mathrm{LPS}}$ ) of $13 \%, K_{\mathrm{GFP}}$ of 20.2 , and high selectivity relatively to the total proteins $(S=20)$, since the majority of contaminants proteins were preferentially partitioned into the bottom (NaPArich) phase (purification factor of 4-fold). It is here demonstrated that the ATPS composed of PEG/NaPA + salts as additives can be used as a first step for the recovery of GFP and removal of contaminants (LPS in part, and most contaminant proteins) from cell lysates by applying a system with low polymer content and using mild conditions.
\end{abstract}

\section{Introduction}

The advent of recombinant DNA technology has increased the production of biomolecules, mainly biopharmaceuticals, using heterologous expression systems. Escherichia coli is one of the most used because of its high growth rates, inexpensive media, and well-known metabolism [1]. However, because the biomolecules produced by $E$. coli are mostly intracellular, an extra cell disruption step is usually required.
Cell disruption releases the naturally occurring lipopolysaccharides (LPS), also known as endotoxins or pyrogens, from the external cover layer, contaminating the released target biomolecules [2,3]. LPS can act as an immunostimulant that activates the complement system causing pyrogenic reactions in humans if present in parenteral drug products. Adverse medical pyrogenic reactions caused by endotoxins are observed in humans at dosages as low as $0.1 \mathrm{ng} / \mathrm{Kg}$ of body weight or 1 endotoxic unit (EU) per $\mathrm{Kg}$. Therefore, because of its potency, the

\footnotetext{
* Corresponding author at: Department of Bioprocesses and Biotechnology, School of Pharmaceutical Sciences, São Paulo State University - FCFar/UNESP, Rodovia Araraquara-Jaú, Km 01 - s/n Campos Ville, Araraquara 14800-903, Brazil.

E-mail address: andremoreni@msn.com (A.M. Lopes).
} 
allowed threshold for endotoxins for most intravenous applications is $5 \mathrm{EU} / \mathrm{Kg} / \mathrm{h}[4,5]$.

Considering the importance of LPS removal and control in the pharmaceutical industry, several attempts to remove LPS contamination from proteins have been made [6], but the removal of LPS remains challenging. The presence of a hydrophobic region of $10-20 \mathrm{kDa}$ per LPS molecule results in a high tendency to self-aggregate into highly stable micelles and vesicles $[7,8]$. The major structural components of the LPS molecule are the hydrocarbon chains (Lipid A), which are anchored at the cell wall, and the core polysaccharide region. Because of the presence of phosphate groups in LPS, the core carries the main electric charge [3]. Several techniques have been applied for LPS removal, such as anion exchange chromatography, ultrafiltration, affinity adsorbents, gel filtration chromatography, and sucrose gradient centrifugation $[9,10]$. Nevertheless, these methods are laborious, and some are quite expensive $[11,12]$. Thus, considering the broad applicability, ease of use and scale-up, and low cost of aqueous two-phase systems (ATPS), they appear to be a feasible platform to separate LPS from target biomolecules selectively in a single downstream step.

In fact, ATPSs have been extensively used to extract/purify a wide range of biomolecules including recombinant biopharmaceuticals [13-18]. In detail, an ATPS is a liquid-liquid extraction system in which two immiscible aqueous-rich phases are formed by the combination of at least two structurally different compounds (polymers, salts, surfactants, sugars, or ionic liquids) above certain concentrations [19]. These systems have been extensively studied in the last few years, particularly for the recovery, partitioning, and purification of a wide range of bioproducts [20-23].

In the last few years, our research group has focused on the recovery of green fluorescent protein (GFP), a biological indicator used as a model protein, from media contaminated with LPS (from $E$. coli) using different types of ATPS [24-26]. Although some previous studies have investigated the removal of LPS [12,27-29], there remains a lack of understanding of selective GFP partitioning in the presence of high LPS loads for polymer-polymer-based ATPSs. Furthermore, although these systems have been well discussed in the literature [30-33], the influence of the addition of electrolytes on GFP partitioning and LPS removal has not been studied. Thus, herein, the presence of electrolytes in a poly(ethylene glycol) (PEG)/sodium poly(acrylic acid) (NaPA)-based ATPS was studied in depth because these additives can change the affinity of the biomolecule and contaminants (i.e., proteins or LPS) for one of the co-existing phases; this is due to the change in water solvation around the polymers or compartmentalization of ions $[30,32,34]$.

In this paper, the simultaneous recovery of GFP and removal of LPS from an E. coli cell lysate using an ATPS composed of PEG with an average molecular weight of $1000 \mathrm{~g} / \mathrm{mol}$ and NaPA with an average molecular weight of $8000 \mathrm{~g} / \mathrm{mol}$ and different salts as additives is proposed. For that purpose, first, the influence of the addition of different electrolytes $\left(\mathrm{NaCl}, \mathrm{Li}_{2} \mathrm{SO}_{4}, \mathrm{KI}\right.$, and $\left.\mathrm{KNO}_{3}\right)$ on the binodal curves of each system was evaluated. Then, GFP partitioning and LPS removal in different types of ATPS both in the presence and absence of salts were investigated. In addition, we studied the influence of high loads of LPS $\left(10^{4}\right.$ and $\left.10^{6} \mathrm{EU} / \mathrm{mL}\right)$ on the pure GFP partitioning using different polymer and salt concentrations. Finally, considering the best results from the initial studies, an optimized ATPS was selected to extract GFP directly from E. coli cell lysate and to remove the LPS and contaminating proteins in a single step, thus validating the applicability of these ATPSs for biopharmaceutical manufacturing processing.

\section{Materials and methods}

\subsection{Materials}

Polyethylene glycol (PEG) with average molecular weight of $1000 \mathrm{~g} / \mathrm{mol}$, was purchased from Merck (Hohenbrunn, Germany).
Polyacrylic acid (NaPA) with average molecular weight of $8000 \mathrm{~g} / \mathrm{mol}$ (45 $\mathrm{wt} \%$ in water) and the salts, sodium chloride $(\mathrm{NaCl})$, lithium sulfate $\left(\mathrm{Li}_{2} \mathrm{SO}_{4}\right)$, potassium iodide (KI), and potassium nitrate $\left(\mathrm{KNO}_{3}\right)$ were purchased from Sigma-Aldrich (St. Louis, MO, USA). LPS from $E$. coli 055:B5 and kinetic chromogenic kit (LAL Kinetic-QCL ${ }^{\circ}$ ) were purchased from Cambrex (Walkersville, MD). Recombinant green fluorescent protein (GFP) was provided by Clontech (95\% purity, Palo Alto, USA). All solutions were prepared in Mcllvaine's buffer, $\mathrm{pH} 7.2$, consisting of $16.4 \mathrm{mM}$ disodium phosphate and $1.82 \mathrm{mM}$ citric acid in water purified by a Millipore Milli-Q system (Bedford, MA). The glassware used was washed in 50:50 (v/v) ethanol/1 M sodium hydroxide bath, followed by a $1 \mathrm{M}$ nitric acid bath, rinsed copiously with Milli-Q water and, finally, dried in oven at $250{ }^{\circ} \mathrm{C}$ for $1 \mathrm{~h}$ for LPS contaminants inactivation. All materials used in the solutions preparations were LPS-free devices. Sterile, disposable plastic ware was used at all times to prevent LPS contamination. The LPS concentration in the Milli-Q water was quantified and found to be below $0.05 \mathrm{EU} / \mathrm{mL}$ (according to the method described in Section 2.3.). All the other reagents were of analytical grade and used as received.

\subsection{Determination of GFP concentration}

The expression, extraction, and purification of recombinant GFP by E. coli DH5- $\alpha$ followed the protocol previously published by Penna et al. [35]. The GFP fluorescence intensity was determined using a spectrofluorometer (RF 5301 PC, Shimadzu Corporation, Kyoto, Japan) with $\lambda_{\text {excitation }}=394 \mathrm{~nm}$ and $\lambda_{\text {emission }}=509 \mathrm{~nm}$.

\subsection{Determination of LPS concentration}

Pure LPS samples were added to the ATPS obtained from E. coli DH5- $\alpha$. The cells were cultured according to the method of Westphal and Jann [36] and purified according to that of Lopes et al. [25]. The LPS concentration in the samples was determined by the kinetic chromogenic method employing a LAL Kinetic-QCL ${ }^{\circledR}$ Kit. All sample dilutions and additions of the lysate to 96-well microtiter plates were performed using a calibrated multichannel pipette with pyrogen-free tips. The plate-based photometric assay $(\lambda=405 \mathrm{~nm})$ was incubated at $37^{\circ} \mathrm{C}$ in an enzyme-linked immunosorbent assay (ELISA) microplate reader (ELx808cse - BIO-TEK Instruments). The positive control was contaminated with an equal LPS concentration of $5.00 \mathrm{EU} / \mathrm{mL}$, and the results for all tests were considered valid whenever the value of recovered LPS concentration was between $50 \%$ and $200 \%$ of this value [37]. For the samples containing polymers (PEG and NaPA) and salts, the interference was considered by subtracting the values obtained for blank assays (i.e., samples without LPS) from the total value obtained for the LPS added to the ATPS.

\subsection{Determination of the total protein concentration}

The total protein concentration was determined by the bicinchoninic acid (BCA) method (Pierce ${ }^{\mathrm{TM}}$ BCA Protein Assay Kit). Samples $(100 \mu \mathrm{L})$ containing proteins and the BCA working reagent $(2 \mathrm{~mL})$, prepared according to the manufacturer's instructions, were added to a test tube. After $30 \mathrm{~min}$, the optical absorbance at $562 \mathrm{~nm}$ was determined by spectrophotometer (F200 Infinito, Tecan System Inc., San Jose, CA) using Milli-Q water as a blank.

\subsection{Determination of the binodal curves}

The binodal curves were determined according to the methodology described by Johansson et al. [32]. For each phase diagram, three stock solutions of $50 \mathrm{wt} \%$ PEG $1000 \mathrm{~g} / \mathrm{mol}, 45 \mathrm{wt} \% \mathrm{NaPA} 8000 \mathrm{~g} / \mathrm{mol}$, and salts $\left(\mathrm{NaCl}, \mathrm{Li}_{2} \mathrm{SO}_{4}, \mathrm{KI}\right.$, or $\mathrm{KNO}_{3}$ at concentrations of 0.05 and $\left.0.25 \mathrm{M}\right)$ were prepared. The stock solutions were mixed in graded glass tubes $(15 \mathrm{~mL})$ with a known concentration of each phase-forming component 
and then centrifuged at $1000 \mathrm{~g}$ for $1 \mathrm{~min}$. Then, the tubes were visually analyzed for the formation of two phases. By titrating with the three stock solutions, it was possible to obtain a binodal curve. Generally, the solutions became turbid on the two-phase side of the binodal curve; however, close to the binodal, the lack of turbidity upon mixing is not a good indication of a one-phase system. This explains the use of centrifugation in these systems. The formation of two-phase systems was generally achieved within few minutes, and after the phase separation $(\sim 30 \mathrm{~min})$, the volumes (in $\mathrm{mL}$ ) were carefully measured.

\subsection{Influence of ATPS phase-forming components on GFP stability}

The fluorescence stability of pure GFP was evaluated in the presence of PEG, NaPA, and salts $\left(\mathrm{NaCl}, \mathrm{Li}_{2} \mathrm{SO}_{4}, \mathrm{KI}\right.$, or $\mathrm{KNO}_{3}$ at 0.25 and $\left.0.50 \mathrm{M}\right)$ in McIlvaine buffer pH 7.2. For this purpose, samples containing 6 and $20 \mathrm{wt} \%$ of PEG and NaPA, respectively, were prepared. GFP was then added to each solution from a concentrated GFP stock solution $(80 \mu \mathrm{g} /$ $\mathrm{mL}$ ), reaching an initial GFP concentration of $10 \mu \mathrm{g} / \mathrm{mL}$. The solutions were then homogenized in an orbital shaker (model 400110, Barnstead/Thermolyne, Dubuque, IA, USA) at $8 \mathrm{rpm}$ for $24 \mathrm{~h}$ at $25^{\circ} \mathrm{C}$. Aliquots of the solutions were withdrawn at time intervals of $0,1,3,9$, and $24 \mathrm{~h}$, and the concentration of GFP was determined according to the procedure described in Section 2.2. All experiments were performed in triplicate, and the standard deviations and the $95 \%$ confidence intervals were calculated. The GFP fluorescence stability $\left(G F P_{\text {stb }}\right)$ of each solution was determined according to the following equation:

$G F P_{\mathrm{stb}}=\left(\frac{[\mathrm{GFP}]_{\mathrm{s}}}{[\mathrm{GFP}]_{\mathrm{i}}}\right) \times 100$

where $[\mathrm{GFP}]_{\mathrm{s}}$ and $[\mathrm{GFP}]_{\mathrm{i}}$ are the GFP concentration $(\mu \mathrm{g} / \mathrm{mL})$ in the sample after the incubation in the presence of ATPS phase-forming components and the initial GFP concentration, respectively.

\subsection{GFP partitioning and LPS removal}

To evaluate the ability of each ATPS for the partitioning of GFP and the removal of LPS, two different compositions in the biphasic region were selected: $i) 12 \mathrm{wt} \%$ PEG 1000/12 wt $\%$ NaPA + salt and ii) $16 \mathrm{wt} \%$ PEG 1000/16 wt $\%$ NaPA 8000 + salt. Eight systems of both compositions were prepared in McIlvaine buffer at $\mathrm{pH} 7.2$ in the presence of two concentrations $(0.05$ and $0.25 \mathrm{M})$ of $\mathrm{NaCl}, \mathrm{Li}_{2} \mathrm{SO}_{4}, \mathrm{KI}$, or $\mathrm{KNO}_{3}$. All phase-forming components, $80 \mu \mathrm{g} / \mathrm{mL}$ of standard GFP ( $95 \%$ purity, Clontech), and $5 \times 10^{6} \mathrm{EU} / \mathrm{mL}$ of pure LPS were added to LPS-free graduated glass tubes $(15 \mathrm{~mL})$ by weight to obtain a total mass of $5 \pm 10^{-4} \mathrm{~g}$. For the tests using $E$. coli cell lysate, the corresponding concentrations of GFP and LPS were, respectively, $75 \mu \mathrm{g} / \mathrm{mL}$ and $2 \times 10^{7} \mathrm{EU} / \mathrm{mL}$. The systems were homogenized in an orbital shaker (model 400110, Barnstead/Thermolyne, Dubuque, IA, USA) at $8 \mathrm{rpm}$ for $15 \mathrm{~min}$ and kept in a thermoregulated device (Polyscience, model 9505) at $25^{\circ} \mathrm{C}$ for $1 \mathrm{~h}$ to reach phase equilibrium. Afterwards, the two coexisting phases were carefully separated using disposable syringes and needles. Samples from the bottom phase were taken after the withdrawal of the top phase, and the respective concentrations of GFP and LPS in each were determined. All experiments were performed in triplicate, the standard deviations, and the 95\% confidence intervals were calculated. The GFP partitioning behavior was assessed according to the GFP partitioning coefficient $\left(K_{\mathrm{GFP}}\right)$, GFP mass balance $\left(M B_{\mathrm{GFP}}\right)$, and percentage of GFP recovered in the PEG-rich phase $\left(R E C_{\mathrm{GFP}}\right)$, as detailed in Eqs. (2)-(4), respectively.

$K_{\mathrm{GFP}}=\frac{[\mathrm{GFP}]_{\mathrm{PEG}-\text { rich phase }}}{[\mathrm{GFP}]_{\mathrm{NaPA}-\text { rich phase }}}$

$$
\begin{aligned}
& M B_{\mathrm{GFP}} \\
& =\left(\frac{[\mathrm{GFP}]_{\mathrm{PEG}-\text { rich phase }} \mathrm{V}_{\mathrm{PEG}-\text { rich phase }}+[\mathrm{GFP}]_{\mathrm{NaPA}-\text { rich phase }} \mathrm{V}_{\mathrm{NaPA}-\text { rich phase }}}{[\mathrm{GFP}]_{\mathrm{i}} \mathrm{V}_{\mathrm{i}}}\right) \\
& \quad \times 100 \\
& R E C_{\mathrm{GFP}}=\left(\frac{[\mathrm{GFP}]_{\mathrm{PEG}-\text { rich phase }} \mathrm{V}_{\mathrm{PEG} \text {-rich phase }}}{[\mathrm{GFP}]_{\mathrm{i}} \mathrm{V}_{\mathrm{i}}}\right) \times 100
\end{aligned}
$$

where $[\mathrm{GFP}]_{\mathrm{PEG}-\text { rich phase, }}[\mathrm{GFP}]_{\mathrm{NaPA}-\text { rich phase, }}$ and $[\mathrm{GFP}]_{\mathrm{i}}$ are GFP concentration in the top (PEG-rich) phase, bottom (NaPA-rich) phase and GFP initial concentration in the system $(\mu \mathrm{g} / \mathrm{mL})$, respectively. $V_{\text {PEG-rich }}$

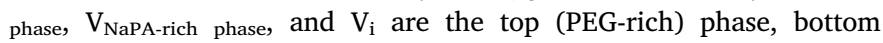
(NaPA-rich) phase and the initial volumes (mL), respectively.

It was also calculated the percentage of LPS removal ( $\left.R E M_{\mathrm{LPS}}\right)$ for the NaPA-rich phase, according to the following equation:

$R E M_{\mathrm{LPS}}=\left(\frac{[\mathrm{LPS}]_{\mathrm{NaPA}-\text { rich phase }} \mathrm{V}_{\mathrm{NaPA}-\text { rich phase }}}{[\mathrm{LPS}]_{\mathrm{i}} \mathrm{V}_{\mathrm{i}}}\right) \times 100$

where $[\mathrm{LPS}]_{\mathrm{NaPA}-\mathrm{rich}}$ phase and $[\mathrm{LPS}]_{\mathrm{i}}$ refer to LPS concentrations (EU/ $\mathrm{mL}$ ) in the bottom (NaPA-rich) phase and LPS initial concentration in the system, respectively. $\mathrm{V}_{\mathrm{NaPA} \text {-rich phase }}$ and $\mathrm{V}_{\mathrm{i}}$ are the bottom (NaPArich) phase and the initial volumes, respectively. As the PEG-rich phase exhibit a large interference in the LPS quantification methodology, the percentage of LPS removal was only inferred by the determination of the LPS concentration in the NaPA-rich phase.

The selectivity in terms of total proteins $(S)$ was also evaluated according to the equation:

$S=\frac{K_{\mathrm{GFP}}}{K_{\mathrm{TP}}}$

where $K_{\mathrm{TP}}$ refer to the total proteins (TP) partitioning in ATPS, similarly calculated according to Eq. (2).

Purification factor of GFP in terms of total proteins $\left(P_{\mathrm{F}}\right)$ was calculated according to the equation:

$P_{\mathrm{F}}=\frac{\left(\frac{[\mathrm{GFP}]_{\text {PEG }}-\text { rich phase }}{\left[{ }^{\mathrm{TP}}\right]_{\mathrm{PEG}}-\text { rich phase }}\right)}{\left(\frac{[\mathrm{GFP}]_{\mathrm{i}}}{[\mathrm{TP}]_{\mathrm{i}}}\right)}$

where $[\mathrm{TP}]_{\mathrm{PEG}-\text { rich phase }}$ and $[\mathrm{TP}]_{\mathrm{i}}$ correspond to the concentration of total proteins in the top (PEG-rich) phase and the initial total protein concentration in the system $(\mu \mathrm{g} / \mathrm{mL})$, respectively.

\subsection{Statistical analysis}

The response variables were $G F P_{\mathrm{stb}}, K_{\mathrm{GFP}}, R E C_{\mathrm{GFP}}$, and $R E M_{\mathrm{LPS}}$. To compare the significance of each condition, R Statistic version 3.3.3 was used to perform one-way ANOVA (with Tukey's test), and to test statistical hypotheses, the significance level was set at 0.05. In addition, Generalized Linear Models (GLM) were fitted for statistical analysis of $K_{\mathrm{GFP}}, R E C_{\mathrm{GFP}}$, and $R E M_{\mathrm{LPS}}$ response to type of salt, salt concentration, and LPS and polymer concentrations. All dataset used for analysis is available at Zenodo (DOI: https://doi.org//10.5281/zenodo.1174377).

\section{Results and discussion}

\subsection{GFP fluorescence stability}

To confirm the biocompatible character of the phase-forming agents in each ATPS, before the GFP partitioning experiments, the stability of GFP in aqueous solutions of each component was evaluated. First, the GFP fluorescence stability in different aqueous solutions of each polymer $(5,10$, and $20 \mathrm{wt} \%)$ and salt $(0.25$ and $0.5 \mathrm{M})$ was assessed separately. The first set of experiments demonstrated that GFP maintains its intrinsic fluorescence over $24 \mathrm{~h}$ in the presence of aqueous solutions of 5, 10, and $20 \mathrm{wt} \%$ PEG 1000 or NaPA 8000 and in the 
$6 \%$ wt PEG/6 \%wt NaPA + $0.25 \mathrm{M}$

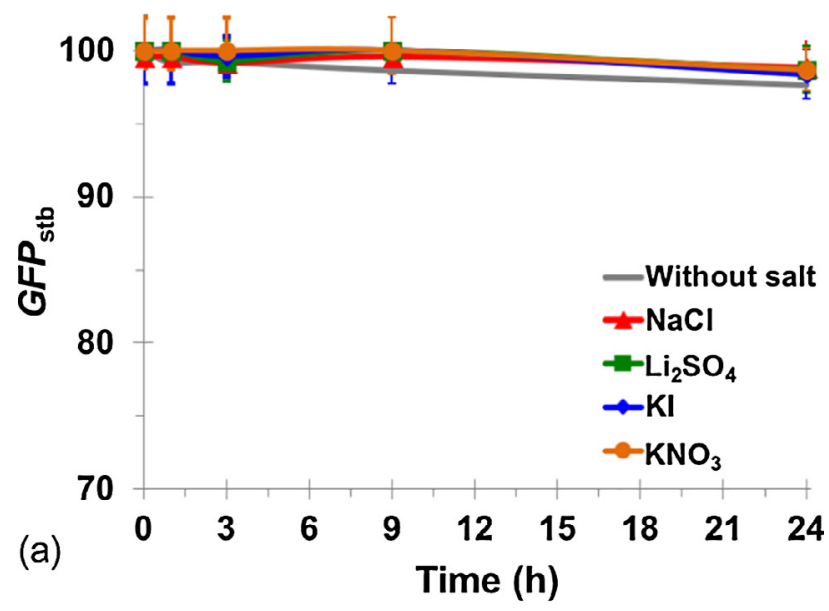

20 \%wt PEG/20 \%wt NaPA + 0.5 M

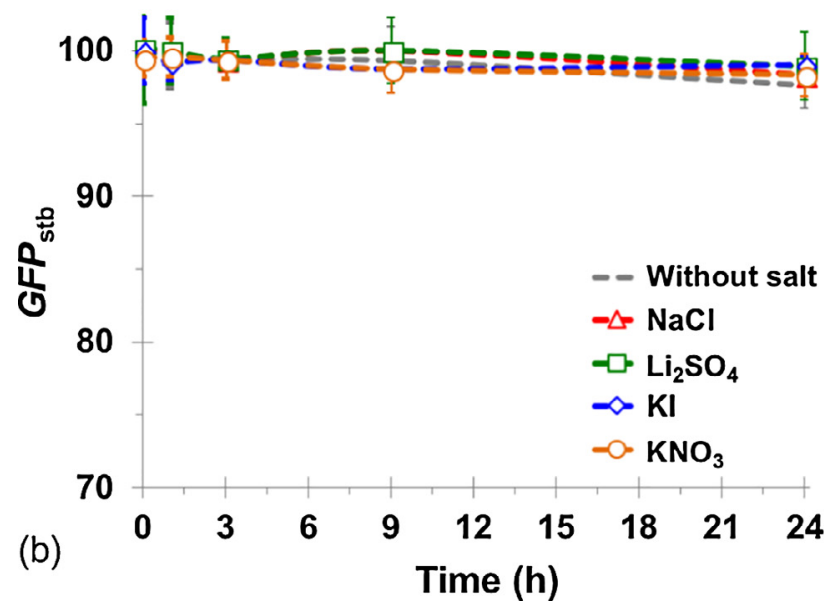

Fig. 1. GFP fluorescence stability ( $\left.G F P_{\text {stb }}\right)$ during $24 \mathrm{~h}$ in the presence of aqueous solutions composed of: (a) $6 \mathrm{wt} \%$ PEG and $6 \mathrm{wt} \% \mathrm{NaPA}+0.25 \mathrm{M}$ of salts; (b) $20 \mathrm{wt} \%$ PEG and $20 \mathrm{wt} \% \mathrm{NaPA}+0.5 \mathrm{M}$ of salts. The following salts were used: $\mathrm{NaCl}(\boldsymbol{\triangle}), \mathrm{Li}_{2} \mathrm{SO}_{4}(\square), \mathrm{KI}(\diamond)$, and $\mathrm{KNO}_{3}(\bigcirc)$. For comparison, the GFP in aqueous solutions without additives were also determined (gray line and gray dotted line). All experiments were prepared with McIlvaine buffer pH 7.2 at $25{ }^{\circ} \mathrm{C}$. The error bars represent $95 \%$ confidence levels for the measurements, but are smaller than the markers. (For interpretation of the references to color in this figure legend, the reader is referred to the web version of this article.)

presence of each electrolyte at 0.25 and $0.5 \mathrm{M}$. On the other hand, in the second set of experiments, GFP $_{\text {stb }}$ was evaluated in mixed aqueous solutions containing the phase-forming agents required for the formation of each ATPS. As depicted in Fig. 1(a) and (b), in the presence of 6 and 20 wt\% PEG 1000 and NaPA 8000, respectively, with and without the addition of each electrolyte $\left(\mathrm{Li}_{2} \mathrm{SO}_{4}, \mathrm{NaCl}, \mathrm{KNO}_{3}\right.$, or $\left.\mathrm{KI}\right), \mathrm{GFP}$ was completely stable.

In general, the PEG/NaPA-based ATPS (with or without additives) showed high values of $G F P_{\text {stb }}$ ( $>98 \%$ ), in which no significant losses of GFP fluorescence occurred even after $24 \mathrm{~h}$ exposure. A one-way analysis of variance (ANOVA) was conducted to compare $G F P_{\text {stb }}$ under each condition. Only two conditions presented a significant protective effect after $24 \mathrm{~h}(p<0.05)[F(49,100)=2.306, p=0.000213]$. Post-hoc comparisons using Tukey's honest significance test (HSD) test indicated that the mean score for the conditions with $\mathrm{Li}_{2} \mathrm{SO}_{4}(M[6 / 6 \mathrm{wt}$ $\%]=98.7 \%$ and $M[20 / 20 \mathrm{wt} \%]=99.0 \%)$ after $24 \mathrm{~h}$ were significantly different from the non-salt test $(M[6 / 6 \mathrm{wt} \%]=97.7 \%$ and $M$ $[20 / 20 \mathrm{wt} \%]=97.7 \%)$. Although significantly different, they represent a small increase in $G F P_{s t b}$ (ca. 1\%). The highly stable character of GFP has been widely reported, and, because of this stability, it is extensively employed for monitoring biological events and as a biosensor to monitor industrial and medical processes (particularly thermal processes) to ensure product quality or process efficacy $[38,39]$. Usually, GFP maintains its fluorescence between $\mathrm{pH} 5.5$ and 11.5 (optimum $\mathrm{pH}$ 8.0) at temperatures below $100^{\circ} \mathrm{C}$, as well as in aqueous solutions containing detergents [40]. Our results clearly demonstrate that GFP can tolerate the processing conditions of the purification/extraction stages using the PEG/NaPA + electrolyte-based ATPS.

Some previous studies have shown that the negative charge of NaPA can interact with the oppositely charged sites of biomolecules through electrostatic interactions, destabilizing or changing their molecular structure and decreasing their biological activity [31,41]. However, at the concentrations studied, GFP maintained its fluorescence activity, which is consistent with previous findings obtained for clavulanic acid, where no significant losses of activity were observed after the exposure of the biomolecule to aqueous solutions of NaPA 8000 at 5 and $15 \mathrm{wt} \%$ [42].

On the other hand, PEG polymers are widely recognized as biocompatible agents and are used in the stabilization of several biomolecules, such as $\alpha$-amylase, glucose oxidase [43], and L-asparaginase [44]. PEG is generally considered biologically inert and safe and is used in both food and drug industries. Previously, de Lencastre Novaes et al. [45] evaluated the relationship between PEG concentration, polymer molecular weight, and temperature on the stability of GFP. As found by us and shown in Fig. 1, GFP was quite stable in the presence of PEG with an average molecular weight of 600 and $4000 \mathrm{~g} / \mathrm{mol}$, where no significant fluorescence losses were observed until $75^{\circ} \mathrm{C}$ [45].

\subsection{Effect of electrolytes on the binodal curves of the PEG/NaPA ATPS}

First, the effects of different electrolytes on the solubility curves of aqueous solutions of PEG 1000 and NaPA 8000 were evaluated. It has been reported that the formation of a polymer-polymer-based ATPS results from polymer incompatibility [46], and, thus, the water structure around the polymers has a significant effect on the thermodynamic equilibrium and, consequently, phase separation [47]. Therefore, changes in the phase-forming agent's composition and the presence of ions can disturb the equilibrium (thus modifying the binodal curve). In particular, in nonionic/ionic polymer mixtures, based on the electroneutrality of the polyelectrolyte, two phases, one with a high concentration of counterions and one enriched in the uncharged polymer, are formed [46]. Johansson et al. [31,32] highlighted that the entropic penalty of counterion compartmentalization in systems composed of PEG (uncharged polymer) and NaPA (negatively charged polymer) results in the minimal concentration of the salt required for the formation of two aqueous phases, a top (PEG-rich) phase and a bottom (NaPArich) phase. Considering that the addition of electrolytes changes the phase separation conditions dramatically, the influence of different inorganic salts on the binodal curve of the systems composed of PEG $1000 \mathrm{~g} / \mathrm{mol}$ and NaPA $8000 \mathrm{~g} / \mathrm{mol}$ at $25^{\circ} \mathrm{C}$ and atmospheric pressure was assessed.

As shown in Fig. 2(a) and (b), independent of the salt concentration, the ability of each electrolyte to induce the formation of a demixing region for the PEG 1000/NaPA 8000-based ATPS follows the order $\mathrm{Li}_{2} \mathrm{SO}_{4}>\mathrm{NaCl} \gg \mathrm{KNO}_{3}>\mathrm{KI}$. As the two-phase region increases (i.e., the binodal curve moves closer to the axis), the ability of the additive to form a biphasic region increases (i.e., a lower polymer concentration is required for phase splitting). Although the liquid-liquid demixing trend is the same for both electrolyte concentrations studied, the influence was more pronounced with a higher amount of salt $(0.25 \mathrm{M})$, as shown in Fig. 2(b). However, it is important to note that $\mathrm{Li}_{2} \mathrm{SO}_{4}$ and $\mathrm{NaCl}$ increased the two-phase region to a greater extent than the other two salts evaluated $\left(\mathrm{KNO}_{3}\right.$ and $\left.\mathrm{KI}\right)$.

Aiming to understand the influence of electrolytes on the phase 

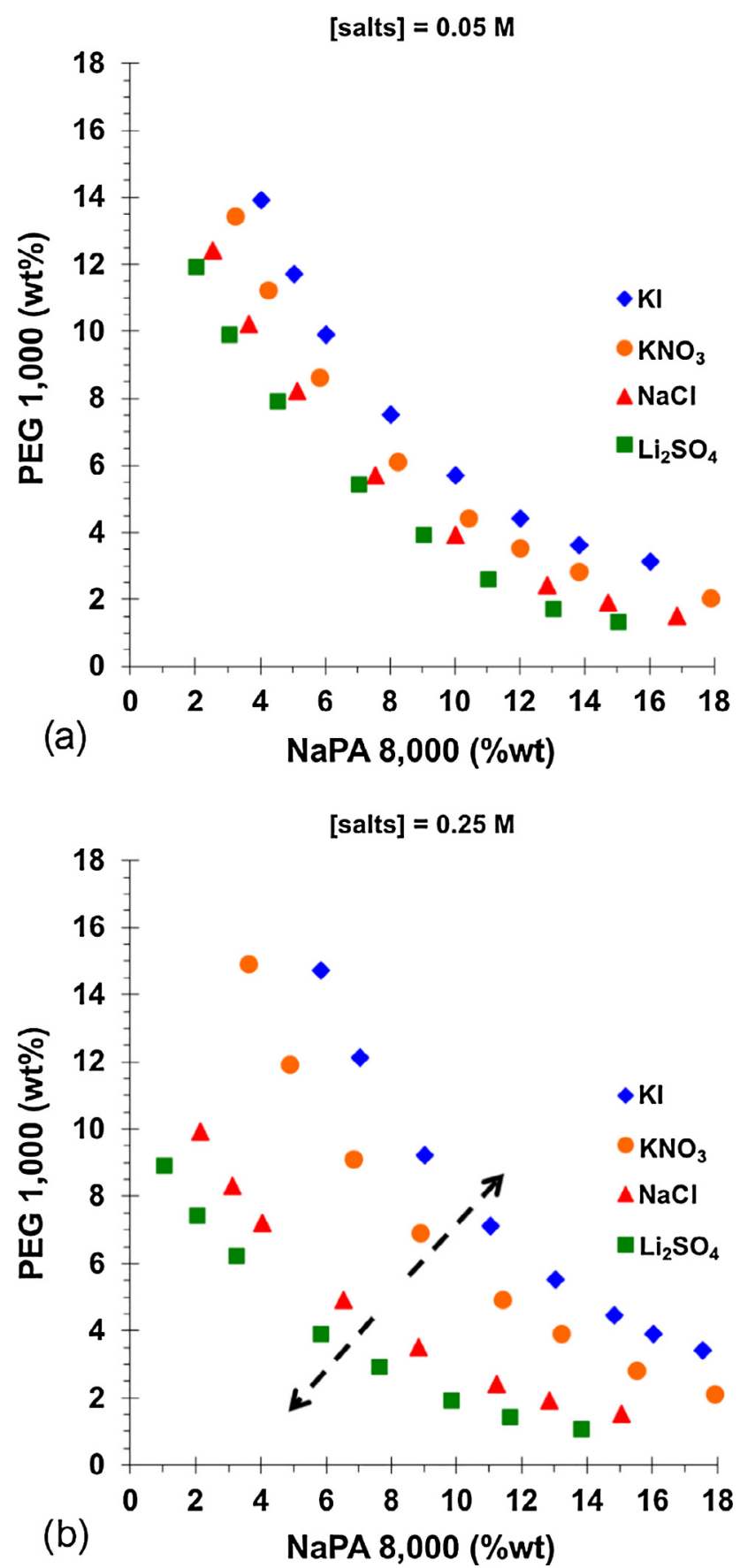

Fig. 2. Binodal curves for ATPS composed of PEG 1000 and NaPA 8000 system in the presence of $\mathrm{KI}(\diamond), \mathrm{KNO}_{3}(\bigcirc), \mathrm{NaCl}(\boldsymbol{\Lambda})$, and $\mathrm{Li}_{2} \mathrm{SO}_{4}(\square)$ at the concentration of the 0.05 (a) and $0.25 \mathrm{M}(\mathbf{b})$. The dotted arrows represent the direction of the displacement of the curves. The ATPS were prepared with McIlvaine buffer $\mathrm{pH} 7.2$ at $25^{\circ} \mathrm{C}$. The error bars correspond to a $95 \%$ confidence interval in the obtained values, but are smaller than the markers.

separation of PEG/NaPA-based ATPS, first, it is important to understand the phase behavior of the polymer/polyelectrolyte/water mixtures. In the absence of salts as additives, the phase demixing of the polymer/polyelectrolyte ATPS resembles the traditional polymer/saltbased ATPS because of the dominant influence of the entropic mixing of the counterions [46]. Thus, when an electrolyte is added to the polymer/polyelectrolyte/water mixtures, a completely different behavior is observed, where two-phases with distinct polymer concentrations and similar (low) ion concentrations are formed [46]. In fact, the relative influence of the polyelectrolyte counterions $\left(\mathrm{Na}^{+}\right)$is reduced because of the addition of smaller ions to the mixture, and the enthalpic repulsion between both polymers is sufficient to allow the phase separation. Because the effect is dependent on the nature (strength and charge) of the ions added, as expected, the ability to induce phase formation is stronger for divalent ions, followed by monovalent salts according to their relative hydrophobicity [32].

Considering that $\mathrm{Na}^{+}$and $\mathrm{K}^{+}$have almost the same hydration ability [48], the different trends observed for the monovalent salts mainly results from the corresponding anion hydrophobicity. Therefore, in the case of the PEG/NaPA-based ATPS studied, the influence of the anions in the formation of two-phases followed the order $\mathrm{SO}_{4}{ }^{2-}>\mathrm{Cl}^{-}>\mathrm{NO}_{3}{ }^{-}>\mathrm{I}^{-}$. The trend in the formation of a demixing region is in close agreement with the relative hydrophilicity/ hydrophobicity of each anion, which, in terms of the solvation free energy (molar Gibbs free energy of hydration $\left(-\Delta G_{\mathrm{hyd}}, \mathrm{kJ} / \mathrm{mol}\right)$ ) of each anion [49], follows the trend $-\Delta G_{\text {hyd }}\left(\mathrm{SO}_{4}{ }^{2-}\right)=1080 \mathrm{~kJ} /$ $\mathrm{mol}>-\Delta G_{\mathrm{hyd}}\left(\mathrm{Cl}^{-}\right)=340 \mathrm{~kJ} / \mathrm{mol}>-\Delta G_{\mathrm{hyd}}\left(\mathrm{NO}_{3}{ }^{-}\right)=300 \mathrm{~kJ} /$ $\mathrm{mol}>-\Delta G_{\text {hyd }}\left(\mathrm{I}^{-}\right)=275 \mathrm{~kJ} / \mathrm{mol}$.

Our results are in agreement with previous reports, for example, the results of Johansson et al. [32], who evaluated the effect of $\mathrm{NaCl}$ and $\mathrm{Na}_{2} \mathrm{SO}_{4}$ in PEG/NaPA systems formed of high-molecular-weight PEG $(2000,6000$, and $8000 \mathrm{~g} / \mathrm{mol})$ and demonstrated that a decrease in the entropy of mixing of the counterions occurs because of the addition of a salt to the system. Santos-Ebinuma et al. [50] also demonstrated that the addition of $\mathrm{NaCl}$ and $\mathrm{Na}_{2} \mathrm{SO}_{4}$ (mono and divalent sodium salts, respectively) as additives to PEG 1000/NaPA 8000 induced similar behavior: an increase in the two-phase region, i.e., the same trend was observed: divalent $\left(\mathrm{Na}_{2} \mathrm{SO}_{4}\right)>$ monovalent salt $(\mathrm{NaCl})$. Gupta et al. [30] studied how the addition of inorganic salts affects the water structures in polymer-polymer (PEG/NaPA and PEG/polyethyleneimine) ATPSs. In particular, they evaluated the effect of potassium and sodium cations on the phase behavior. They explained the effect of electrolyte ions in terms of the making and breaking of the water structure.

In this section, the main objective was not to extensively study the effect of salts on binodal curves but understand how the electrolytes evaluated influence the binodal curve and the corresponding biphasic region. Thus, with each phase diagram, it was possible to establish the exact PEG/NaPA compositions for further GFP partitioning and LPS removal studies.

\subsection{Effect of the salt on GFP partitioning using PEG/NaPA-based ATPS}

According to Silva et al. [51], ATPSs composed of PEG with a molecular weight from 400 to $1500 \mathrm{~g} / \mathrm{mol}$ are known to accommodate proteins easily. Previous studies of GFP partitioning using PEG/NaPAbased ATPSs [31] have also suggested that low-molecular-weight PEG could enhance the partitioning of GFP into a PEG-rich phase. Thus, the partitioning of pure GFP using an ATPS comprising PEG $1000 \mathrm{~g} / \mathrm{mol}$ and $\mathrm{NaPA} 8000 \mathrm{~g} / \mathrm{mol}$ in the presence of different electrolytes was firstly evaluated.

As shown by the data in Fig. $3(\mathrm{a}), K_{\mathrm{GFP}}$ was higher than 1.0 for all conditions investigated, indicating that GFP is preferentially partitioned into the top (PEG-rich) phase. It is important to consider that the mass balances $\left(M B_{\mathrm{GFP}}\right)$ for all the systems were approximately $100 \%$ (data not shown). These results are in accordance with the previous GFP fluorescence stability tests, which demonstrated that GFP maintains its fluorescence intensity in the presence of aqueous solutions of the polymer-polymer + salt components.

The $K_{\mathrm{GFP}}$ values varied between 2.5 and 33.3, whereas $R E C_{\mathrm{GFP}}$ varied between $36 \%$ and $83 \%$ (Fig. 3(b)). Analyzing the data from Fig. 3(a) and (b) in detail, it is evident that the PEG concentration, as well as the type and concentration of each salt, has a strong influence on the GFP partitioning, particularly for systems using $\mathrm{Li}_{2} \mathrm{SO}_{4}$ and $\mathrm{NaCl}$ as additives. The highest $K_{\mathrm{GFP}}$ values were obtained with $0.25 \mathrm{M} \mathrm{Li}_{2} \mathrm{SO}_{4}$ and $\mathrm{NaCl}$ : 33.3 and 27.2, respectively. These conditions also presented 


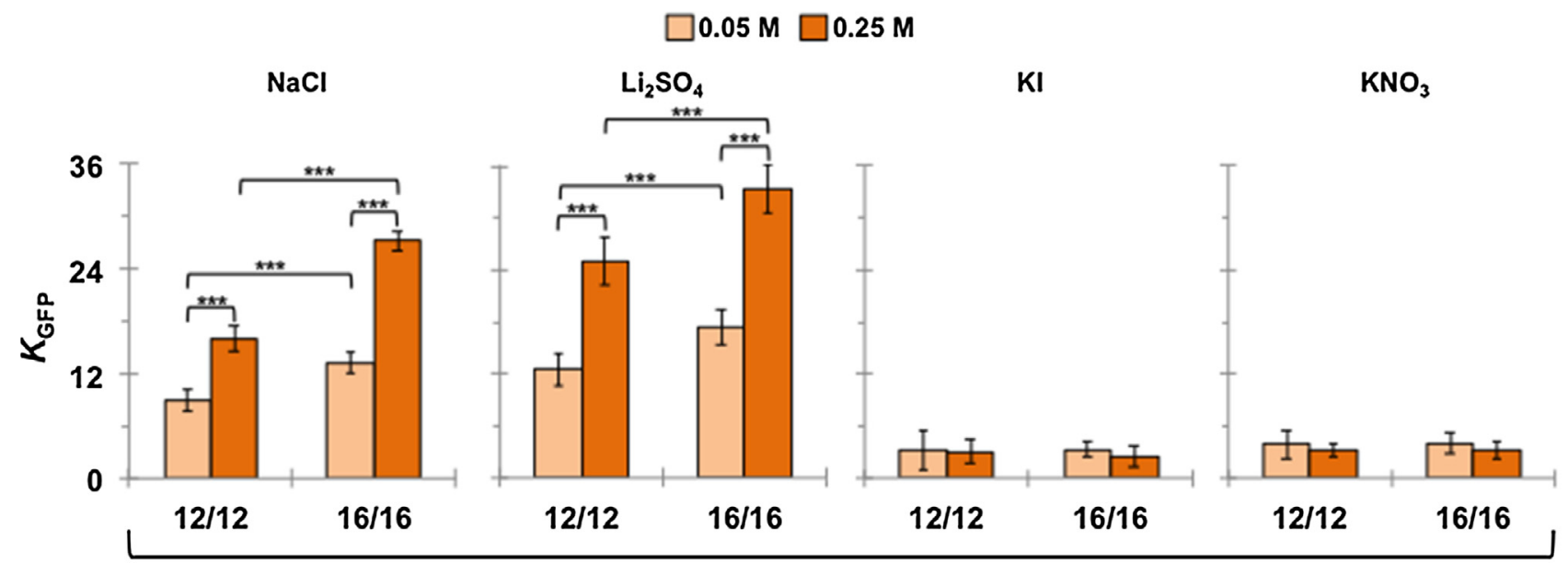

(a)

PEG/NaPA (wt\%)

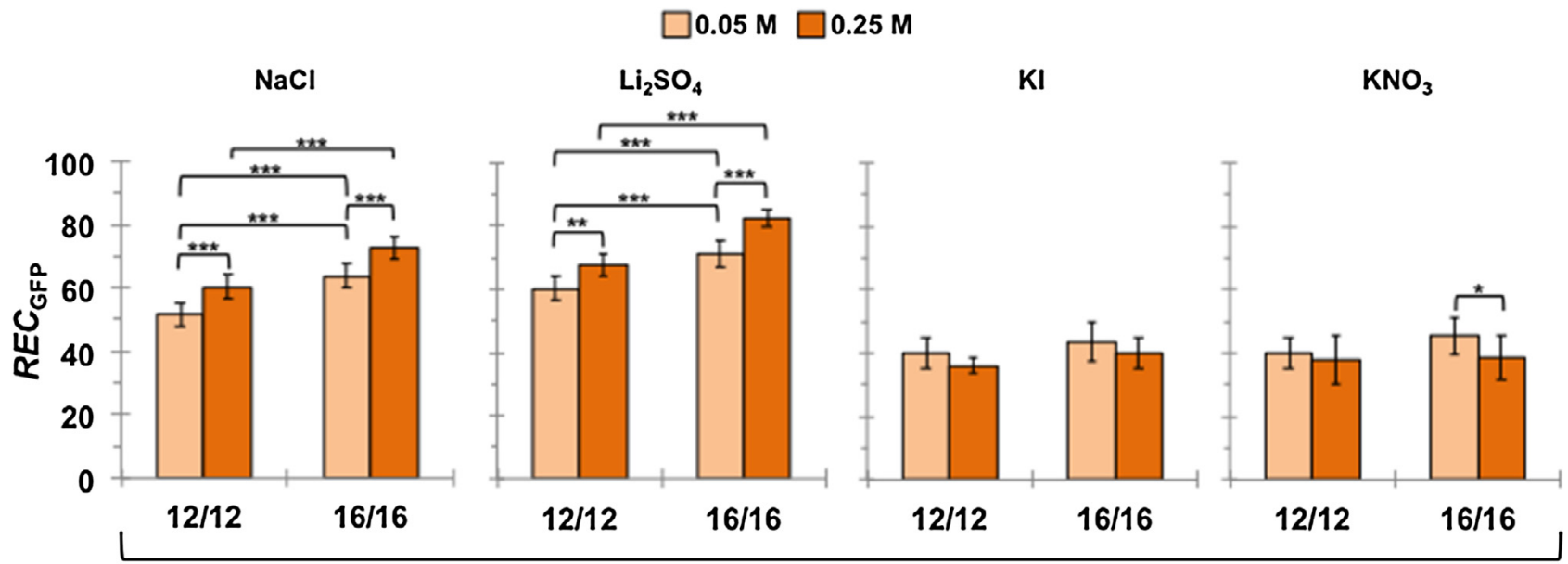

(b)

PEG/NaPA (wt\%)

(c)

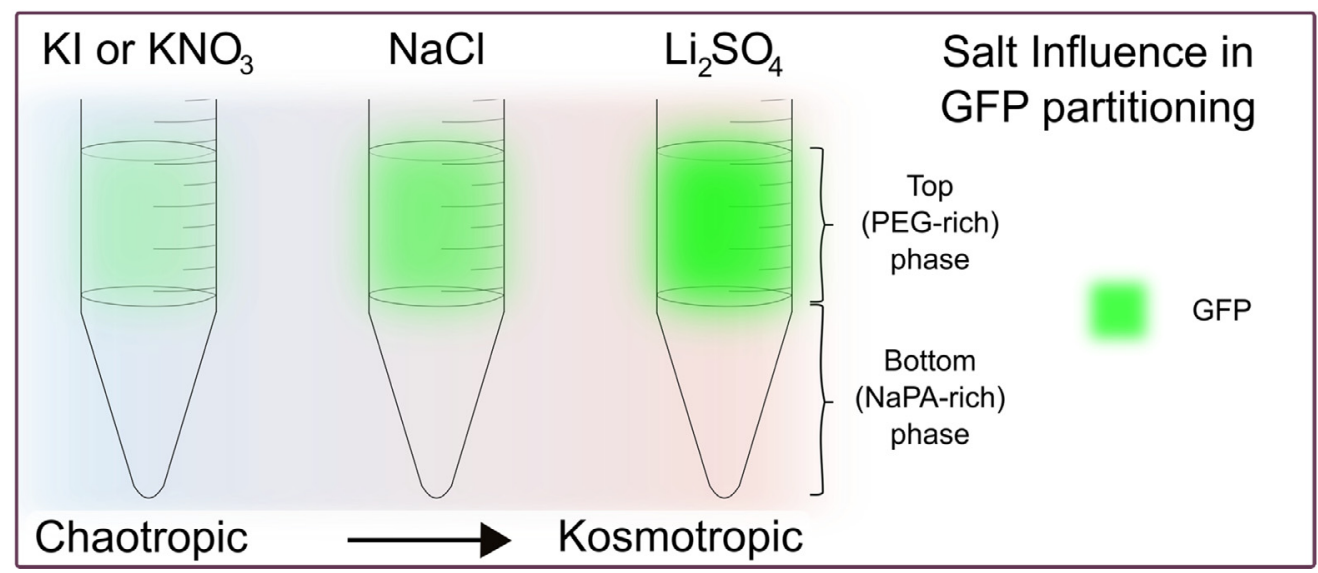

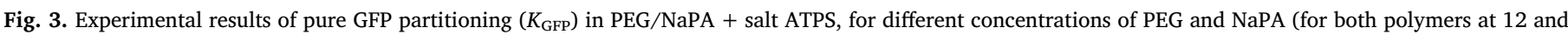

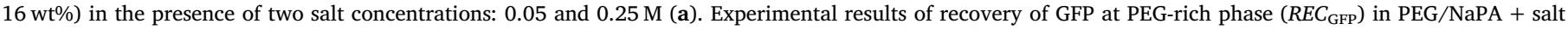

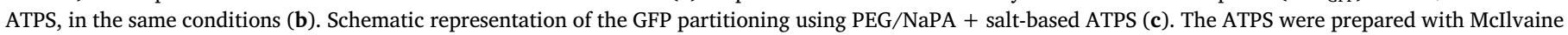

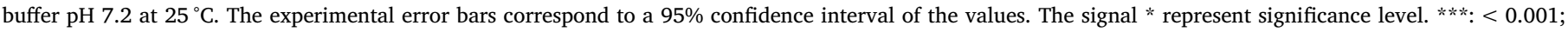
$* *:<0.01$.

the highest $R E C_{\mathrm{GFP}}$ values of $83 \%$ and $73 \%$, respectively. For $\mathrm{NaCl}$ and $\mathrm{Li}_{2} \mathrm{SO}_{4}$, a reduction in the polymer concentration, from 16 to $12 \mathrm{wt} \%$, of both PEG and NaPA, reduced the partitioning of the target molecule for the PEG-rich phase. However, in the case of the other two electrolytes
( $\mathrm{KI}$ and $\mathrm{KNO}_{3}$ ), which correspond to the two ATPSs that exhibited the lowest $K_{G F P}$ values, the reduction in the polymer composition did not affect the GFP partitioning; that is, the values were not statistically different. 


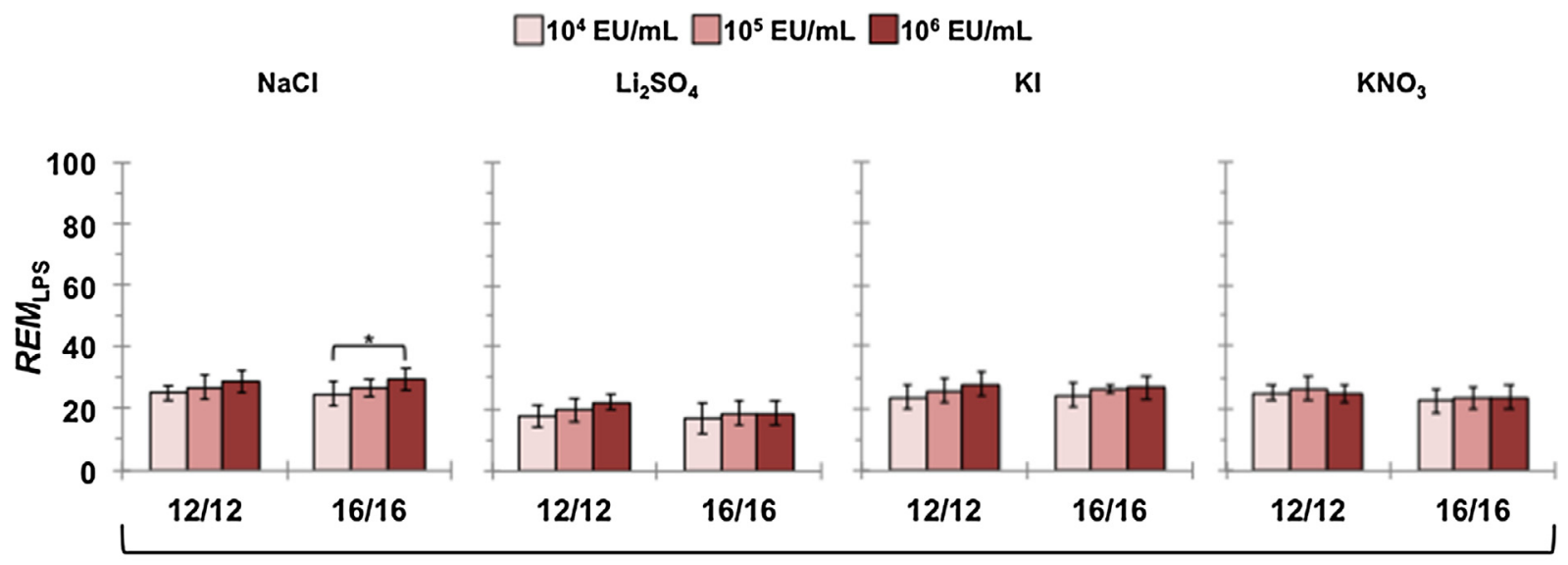

(a)

PEG/NaPA $(w t \%)+0.05 M$

$\square 10^{4} \mathrm{EU} / \mathrm{mL} \square 10^{5} \mathrm{EU} / \mathrm{mL} \square 10^{6} \mathrm{EU} / \mathrm{mL}$

$\mathrm{NaCl}$

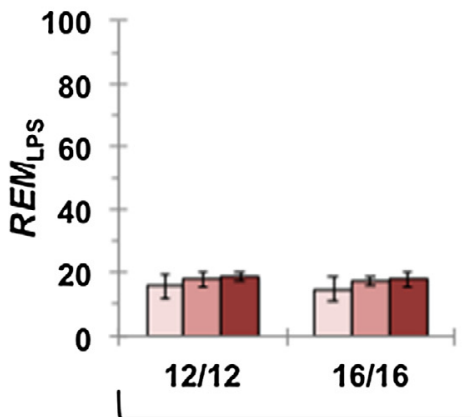

(b)
$\mathrm{Li}_{2} \mathrm{SO}_{4}$

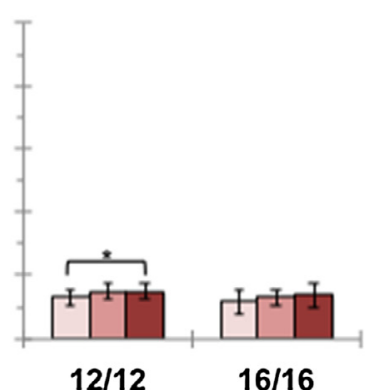

KI

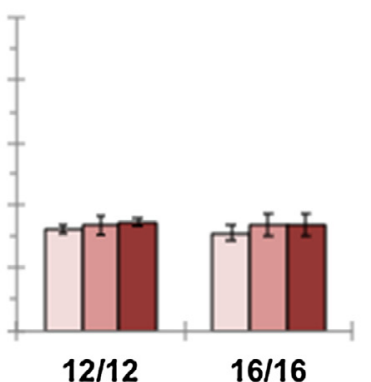

$\mathrm{KNO}_{3}$

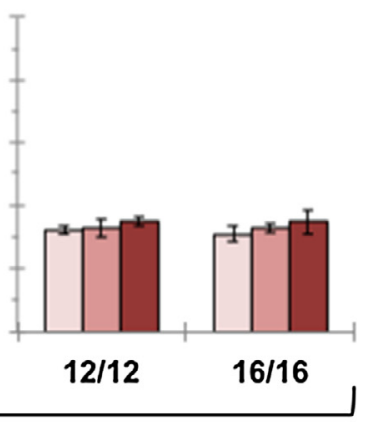

PEG/NaPA $(w t \%)+0.25 \mathrm{M}$

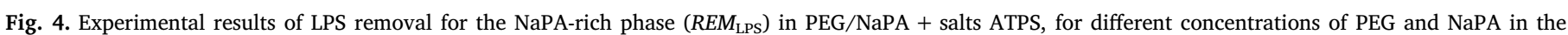

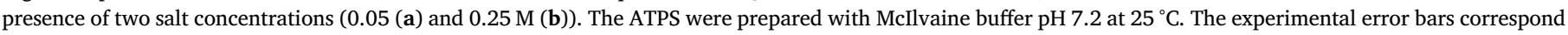
to a $95 \%$ confidence interval of the values. The signal $*$ represent significance level. $*:<0.05$.

Because NaPA is negatively charged, it can create repulsive or attractive interactions depending on the charge of the target biomolecules. Thus, considering that GFP is an acidic protein $(\mathrm{pI}=4.6-5.4)$, under the conditions evaluated ( $\mathrm{pH} 7.2)$, it has an overall negative charge and is, thus, excluded from the bottom (NaPA-rich) phase to the PEG-rich phase (as demonstrated by $K_{\mathrm{GFP}} \gg 1$ ). Previously, Johansson et al. [31,52] showed that negatively charged GFP [31] and hemoglobin [52] are preferentially partitioned into the PEG-rich phase, and this behavior is more pronounced with $\mathrm{Na}_{2} \mathrm{SO}_{4}$ than $\mathrm{NaCl}$. These previous findings are in accordance with those obtained in this work. Systems with $0.25 \mathrm{M} \mathrm{Li}_{2} \mathrm{SO}_{4}$ as an electrolyte exhibited in average a significant increase of 8 in $K_{\mathrm{GFP}}$ values $\left(p=9.02 \times \mathrm{E}^{-14}\right)$ when compared to $0.25 \mathrm{M} \mathrm{NaCl}$ results. Similarly, Pereira et al. [42] also demonstrated that the negatively charged clavulanic acid is preferentially partitioned in the PEG-rich phase because of electrostatic repulsion when PEG/NaPA-based ATPSs with $\mathrm{NaCl}$ or $\mathrm{Na}_{2} \mathrm{SO}_{4}$ as additives were used. Based on these considerations, it is evident that the partitioning of the GFP in the PEG/NaPA + salt-based ATPS is mainly controlled by the electrostatic repulsion of the negatively charged bottom (NaPArich) phase toward GFP.

To understand how the electrolyte nature affects GFP partitioning to the PEG-rich phase, we examined the results obtained with the systems using $\mathrm{Li}_{2} \mathrm{SO}_{4}$ and $\mathrm{NaCl}$ as ATPS additives, which enhanced the partitioning towards the top phase. Probably, the repulsive electrostatic forces in ATPSs with sulfate- and chloride-based salts are more pronounced than those in the presence of iodate and nitrate-based salts. To understand the strength of the repulsive interactions in the PEG/
NaPA + salt-based ATPS toward charged biomolecules, it is important to know how the $\mathrm{pH}$ and salt type affect the separation of biomolecules. In the 1970s, it was demonstrated that both parameters affect the partitioning of charged biomolecules significantly [47]. The partitioning of the biomolecules to the more "hydrophobic" of the coexisting phases is facilitated if the more "hydrophobic" salt ion is also the counterion of the protein. In contrast, if the co-ion exhibits a more hydrophobic character, the reverse effect occurs, and the partitioning of the negatively charged protein to the hydrophobic phase is decreased [47].

Although both PEG and NaPA-rich phases are mainly composed of water, the PEG-rich phase exhibits higher relative "hydrophobicity". In addition, according to the Hofmeister series [53], the inorganic anions with low charge can be arranged in the following sequence from kosmotropic to chaotropic: $\mathrm{SO}_{4}{ }^{2-}>\mathrm{Cl}^{-}>\mathrm{NO}_{3}{ }^{-}>\mathrm{I}^{-}$. These anions are not "truly" hydrophobic, but they act "hydrophobically" in the sense that they prefer the more hydrophobic phase (in an ATPS) and have relatively higher solvation energies [49] because of their significantly higher polarizability. As reviewed by Karlström [54], this polarizability favors anisotropic solvation, which is facilitated by the presence of non-polar regions. Thus, it is not the ion itself or its strongly bound water molecules that are hydrophobic but rather an intermediate water solvation region that acts "hydrophobically" [31]. For this reason, GFP (negatively charged under the experimental conditions) competes with these anions (mainly with $\mathrm{I}^{-} \approx \mathrm{NO}_{3}{ }^{-}>\mathrm{Cl}^{-}$) for partitioning to the PEG-rich phase. Because the competition between the anionic salts and negatively charged GFP decreases as 
$\mathrm{SO}_{4}{ }^{2-}>\mathrm{Cl}^{-}>\mathrm{NO}_{3}{ }^{-} \approx \mathrm{I}^{-}$, the use of $\mathrm{Li}_{2} \mathrm{SO}_{4}$ and $\mathrm{NaCl}$ salts as electrolytes enhances the $K_{\mathrm{GFP}}$, as shown schematically in Fig. 3(c).

\subsection{Effect of the salt on LPS removal using PEG/NaPA-based ATPS}

In addition to the study of GFP partitioning, the ability of each ATPS to remove LPS was also assessed. For that purpose, initially, the partitioning of pure LPS at three different concentrations $\left(10^{4}, 10^{5}\right.$, and $10^{6} \mathrm{EU} / \mathrm{mL}$ ) was carried out using the previous PEG/NaPA + salt-based ATPS.

The results demonstrate that the LPS molecules are partitioned preferentially in the PEG-rich phase, i.e., $R E M_{\mathrm{LPS}}$ values lower than $50 \%$ for the NaPA-rich phase. Overall, the PEG/NaPA systems yielded $R E M_{\text {LPS }}$ values between $12 \%$ and $35 \%$ (Fig. 4(a) and (b)). The highest $R E M_{\text {LPS }}$ values were obtained with the systems with $0.25 \mathrm{M}$ of $\mathrm{KI}$ or $\mathrm{KNO}_{3}$ and in the presence of $10^{6} \mathrm{EU} / \mathrm{mL}$ of LPS (REM $M_{\mathrm{LPS}}$ of ca. $\left.35 \%\right)$. On the other hand, when the PEG/NaPA-based ATPS was used with $0.25 \mathrm{M}$ of $\mathrm{NaCl}$ or $\mathrm{Li}_{2} \mathrm{SO}_{4}$ (at the same LPS concentration), the $R E M_{\mathrm{LPS}}$ were significant lower $\left(p<2 \times \mathrm{E}^{-16}\right)$, reaching ca. $19 \%$ and $15 \%$ removal, respectively. Interestingly, increasing the additive concentration (from 0.05 to $0.25 \mathrm{M}$ ) induced two completely opposite effects depending on the type of salt. In the systems using $\mathrm{KI}$ or $\mathrm{KNO}_{3}$, the $R E M_{\mathrm{LPS}}$ values increased $7.4 \%\left(p<2 \times \mathrm{E}^{-16}\right)$ for $\mathrm{KI}$ and $8.8 \%$ to $\mathrm{KNO}_{3}$ $\left(p<2 \times \mathrm{E}^{-16}\right)$ with increasing electrolyte concentration. In the case of the addition of $\mathrm{NaCl}$ or $\mathrm{Li}_{2} \mathrm{SO}_{4}$, a decrease was observed, LPS removal with increased $\mathrm{NaCl}$ concentration reduced by $9.7 \%\left(p<2 \times \mathrm{E}^{-16}\right)$, while $5.4 \%$ with $\mathrm{Li}_{2} \mathrm{SO}_{4}\left(p=1.53 \times \mathrm{E}^{-13}\right)$.

Although the LPS load in the system weakly affect the LPS removal in ATPS, a significant $\left(p<7.77 \times \mathrm{E}^{-8}\right.$ ), but small increase of $1.3 \%$ with increasing LPS concentration was observed (REM $M_{\mathrm{LPS}}$ with $10^{6} \mathrm{EU} /$ $\mathrm{mL}>R E M_{\mathrm{LPS}}$ with $10^{5} \mathrm{EU} / \mathrm{mL}>R E M_{\mathrm{LPS}}$ with $\left.10^{4} \mathrm{EU} / \mathrm{mL}\right)$. The influence of the polymer concentration was also evaluated (12/12 and $16 / 16 \mathrm{wt} \%$ ) with the higher concentration weakly reducing LPS removal by around $0.8 \%(p<0.05)$.

Taking into consideration the obtained results, it seems that the predominant effects controlling LPS removal are the type and concentration of the salts used as additives, not the polymer concentration. The low values of $R E M_{\mathrm{LPS}}$ indicate that LPS molecules are mainly partitioned in the PEG-rich phase, similar to GFP. In fact, in the presence of $\mathrm{Li}_{2} \mathrm{SO}_{4}$ and $\mathrm{NaCl}$, higher concentrations of LPS were found in the top (PEG-rich) phase, which corresponds to the highest $K_{\mathrm{GFP}}$ obtained under the same conditions (Fig. 3(a)). In contrast, in the case of the addition of $\mathrm{KI}$ and $\mathrm{KNO}_{3}$ as additives, lower concentrations of LPS (in comparison to $\mathrm{Li}_{2} \mathrm{SO}_{4}$ and $\mathrm{NaCl}$ additives) were found in the top (PEGrich) phase, in agreement with the lowest $K_{\mathrm{GFP}}$ under the same conditions (Fig. 3(a)). Considering these results, it is evident that LPS molecules have a similar partitioning mechanism to GFP when PEG/ $\mathrm{NaPA}+$ salts are used as an extractive platform.

Although the previous data for LPS removal indicate that LPS is mainly concentrated in the PEG-rich phase (as GFP), the partitioning studies evaluated only the partitioning of both biomolecules as single solutes in the system. Thus, considering that the presence of a complex matrix with more than one biomolecule can affect the partitioning mechanism, we evaluated the effect of the presence of LPS molecules on the partitioning behavior of pure GFP. In this step, considering that there was a weak influence of the polymer concentration and to reduce the amount of phase-forming agents used in the formulation of each ATPS, the systems composed of $12 \mathrm{wt} \%$ PEG/12 wt $\%$ NaPA with $0.25 \mathrm{M}$ of each salt were selected. For all the systems, the presence of lower and higher LPS concentrations $\left(10^{4}\right.$ and $10^{6} \mathrm{EU} / \mathrm{mL}$, respectively) was also assessed. For comparison, the $K_{\mathrm{GFP}}$ values in the absence of LPS (i.e., the $K_{\mathrm{GFP}}$ values shown in Fig. 3(a)) are also included in Fig. 5(a).

In general, the partitioning of pure GFP in the PEG-rich phase decreased with increasing LPS concentration, as shown in Fig. 5(a). The decreases in the $K_{\mathrm{GFP}}$ values of the ATPSs with $\mathrm{Li}_{2} \mathrm{SO}_{4}$ or $\mathrm{NaCl}$ as additives were more pronounced than those with $\mathrm{KI}$ or $\mathrm{KNO}_{3}$. The $K_{\mathrm{GFP}}$ values of the PEG/NaPA-based ATPSs with $0.25 \mathrm{M}$ of $\mathrm{NaCl}$ or $\mathrm{Li}_{2} \mathrm{SO}_{4}$ loaded with $10^{6} \mathrm{EU} / \mathrm{mL}$ of LPS showed the highest decrease, having corresponding $K_{\mathrm{GFP}}$ values of approximately of 13.0 and 22.0, respectively, as shown schematically in Fig. 5(b). On the other hand, the addition of LPS to the ATPSs using $\mathrm{KI}$ or $\mathrm{KNO}_{3}$ as electrolytes had almost no effect on $K_{\mathrm{GFP}}$ (in comparison with the system in the absence of LPS), and no statistically significant difference between the values was observed.

Previously, it was reported that non-specific LPS-protein interactions can occur $[55,56]$, and the addition of LPS can even induce GFP aggregation [26]. The addition of LPS increased the aggregate diameter (to approximately $60 \mathrm{~nm}$ ). Although the hydrodynamic radius $\left(R_{\mathrm{p}}\right)$ of GFP is around $8.0 \mathrm{~nm}$, it is possible that, upon LPS addition ( $>10^{4} \mathrm{EU} /$ $\mathrm{mL}$ ), some LPS-GFP aggregates can be formed, increasing the corresponding aggregate size. Thus, because of the high $R_{p}$ values of the LPSGFP aggregates, some unfavorable excluded-volume effects (from the PEG-rich phases) can occur, thus reducing the $K_{\mathrm{GFP}}$ values in the presence of LPS ( $K_{\mathrm{GFP}}$ without LPS $>K_{\mathrm{GFP}}$ with $10^{4} \mathrm{EU} / \mathrm{mL}$ LPS $>K_{\mathrm{GFP}}$ with $10^{6} \mathrm{EU} / \mathrm{mL}$ LPS).

Despite this, it is important to note that although a decrease in the partitioning of the target biomolecule for the two systems with the highest partitioning ability occurs, the $K_{\mathrm{GFP}}$ values obtained are significant, demonstrating that these PEG/NaPA + salt-based ATPSs may still be a feasible option for the recovery of GFP from complex media.

\subsection{The key systems for GFP purification from E. coli cell lysate}

After evaluating the ability of each ATPS for the partitioning of pure GFP and the removal of LPS, the efficiency of the best system for the purification of GFP from a more complex, real matrix was assessed. The recovery of GFP from $E$. coli cell lysate was determined for the systems composed of $12 \mathrm{wt} \% \mathrm{PEG} / 12 \mathrm{wt} \% \mathrm{NaPA}+0.25 \mathrm{M} \mathrm{Li}_{2} \mathrm{SO}_{4}$ because this system achieved high values of $K_{\mathrm{GFP}}(>24.0)$ and $R E C_{\mathrm{GFP}}$ (ca. 70\%) for pure GFP and required the lowest polymer concentrations for ATPS formation. The GFP and LPS concentrations present in the cell lysate were $75 \mu \mathrm{g} / \mathrm{mL}$ and $2 \times 10^{7} \mathrm{EU} / \mathrm{mL}$, respectively. The results of GFP purification from cell lysate are shown in Table 1 .

Considering that GFP was recovered from a complex matrix containing a large number of contaminants (such as LPS, proteins, and residual sugars), the GFP partitioning ability of the PEG/ $\mathrm{NaPA}+\mathrm{Li}_{2} \mathrm{SO}_{4}$-based ATPS was significant $\left(K_{\mathrm{GFP}}=20.2 \pm 0.05\right)$, almost the same value as previous studies using pure GFP $\left(K_{\mathrm{GFP}}=22 \pm 0.05\right)$. The use of this platform allowed the recovery of almost $83 \%$ of the GFP $\left(R E C_{\mathrm{GFP}}\right)$ in the PEG-rich phase in a single step with the removal of $13 \%$ of the LPS contaminant. Although the $R E M_{\mathrm{LPS}}$ value is quite low, it is important to highlight that the cell lysate also contains other contaminants, particularly other proteins, that should be removed during downstream processing. Thus, we evaluated the ability of the PEG/NaPA $+\mathrm{Li}_{2} \mathrm{SO}_{4}$-based ATPS to purify the GFP selectively from other contaminant proteins present in the cell lysate. The values of the purification factor $\left(P_{\mathrm{F}}=4\right.$-fold increase) and selectivity $(S=$ $20 \pm 0.5$ ) demonstrate the excellent ability of this ATPS to remove the protein contaminants and consequently, purify the GFP from the contaminated $E$. coli cell lysate.

Furthermore, an important point should be highlighted. Because of the amphiphilic characteristics of the LPS molecules (hydrophilic character of the oligosaccharide portion and hydrophobic character of the Lipid A portion), in an ATPS environment, the LPS molecules show amphiphilic behavior similar to a surfactant and tend to aggregate under certain conditions, forming micellar aggregates. Thus, LPS micelles are highly partitioned in the same phase as the target biomolecule (PEG-rich phase), and, consequently, the contaminant proteins are concentrated in the opposite NaPA-rich phase, increasing the purification yield. A representative scheme of all the partitioning mechanisms that occur in our PEG/NaPA + salt-based ATPS experiments is shown in a video (see in Appendix A. Supplementary data). 


\section{Without LPS (from Fig. 3 a) $[0.25 \mathrm{M}]) \square 10^{4} \mathrm{EU} / \mathrm{mL} \square 10^{6} \mathrm{EU} / \mathrm{mL}$}

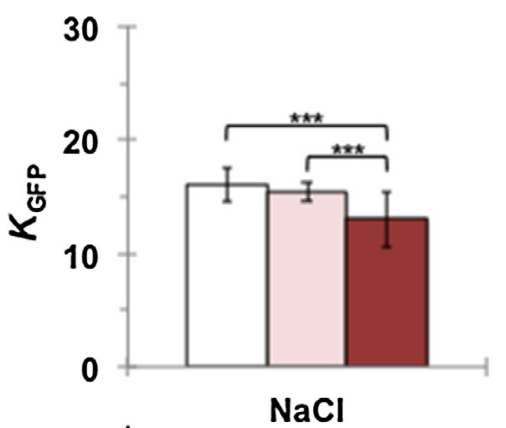

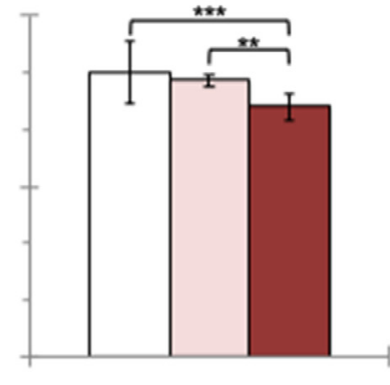

Li2SO4

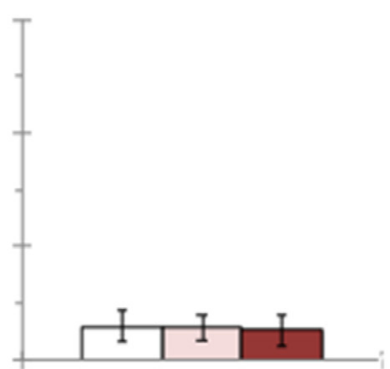

KI

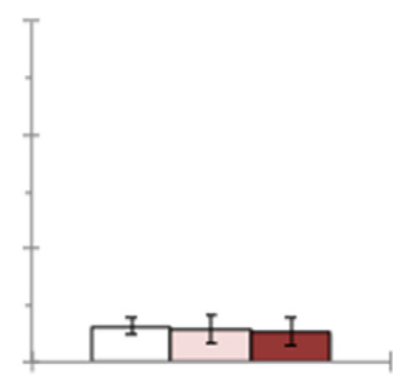

KNO3

(a)

$12 \%$ PEG/12\% NaPA $(w t \%)+0.25 \mathrm{M}$

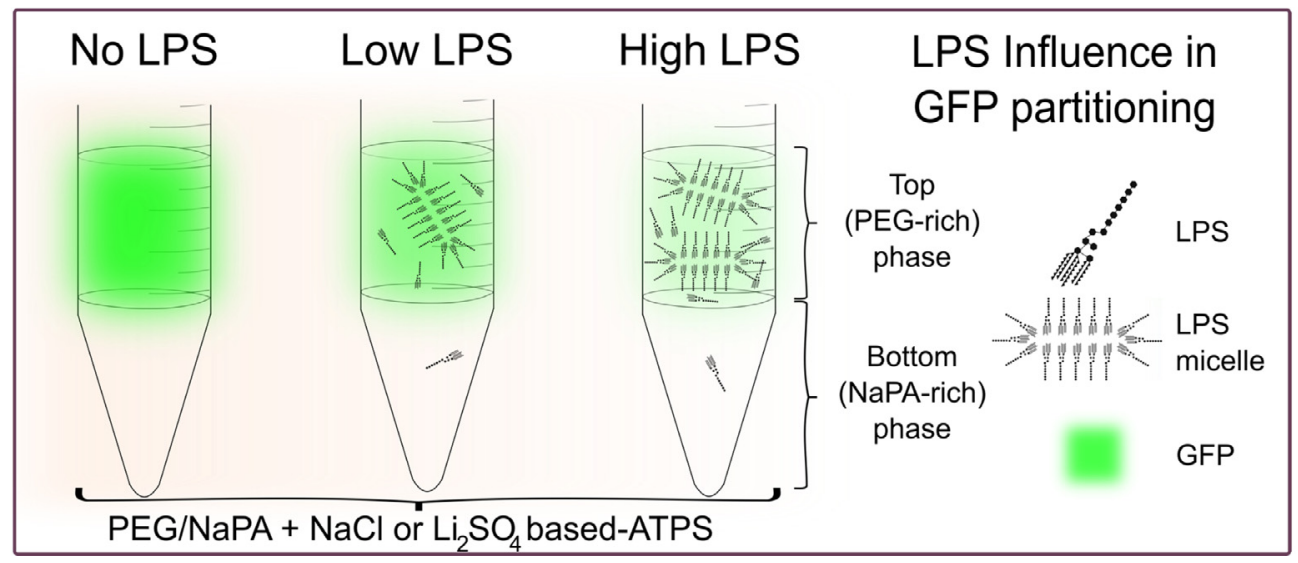

Fig. 5. Experimental results of pure GFP partitioning $\left(K_{\mathrm{GFP}}\right)$ with $12 \mathrm{wt} \% \mathrm{PEG} / 12 \mathrm{wt} \% \mathrm{NaPA}+0.25 \mathrm{M}$ of salts ATPS in the presence of LPS concentrations: $10^{4}$ and $10^{6} \mathrm{EU} / \mathrm{mL}$ (a). Schematic representation of the GFP partitioning with or without LPS using PEG/NaPA + salt-based ATPS (b). The ATPS were prepared with McIlvaine buffer $\mathrm{pH} 7.2$ at $25^{\circ} \mathrm{C}$. The experimental error corresponds to a $95 \%$ confidence interval in the obtained values. The signal * represent significance level. $* * *:<0.001 ; * *:<0.01$.

Table 1

Experimental results of GFP recovery $\left(K_{\mathrm{GFP}}\right.$ and $\left.R E C_{\mathrm{GFP}}\right)$ and LPS removal $\left(R E M_{\mathrm{LPS}}\right)$ from cell lysate of $E$. coli using PEG/NaPA + salts-based ATPS; and the respective values of purification factor $\left(P_{\mathrm{F}}\right)$ and selectivity relatively to total proteins $(S)$. The ATPS were prepared with Mcllvaine buffer $\mathrm{pH} 7.2$ at $25^{\circ} \mathrm{C}$. The experimental errors correspond to a $95 \%$ confidence interval of the values.

\begin{tabular}{ll}
\hline Parameters & $12 \mathrm{wt} \% \mathrm{PEG} / 12 \mathrm{wt} \% \mathrm{NaPA}+0.25 \mathrm{M} \mathrm{Li}_{2} \mathrm{SO}_{4}$ \\
\hline$K_{\mathrm{GFP}}$ & $20.2 \pm 0.05$ \\
$R E C_{\mathrm{GFP}}$ & $83 \pm 1.0$ \\
$R E M_{\mathrm{LPS}}$ & $13 \pm 1.8$ \\
$P_{\mathrm{F}}$ & $4 \pm 1.1$ \\
$S$ & $20 \pm 0.5$ \\
\hline
\end{tabular}

The excellent values obtained for most of the partitioning parameters under this study prove that this ATPS can be used as an effective platform for the extraction and purification of GFP produced from $E$. coli expression systems. However, considering that LPS removal is still one of the major challenges in biopharmaceutical production processes, in parallel to this study, we have evaluated the use of aqueous twophase micellar systems (ATPMS) that can increase the LPS removal values and remove/separate this contaminant from the target biomolecule (GFP). A similar approach to that described here has been applied to evaluate the influence of electrolytes, as well as the stability of GFP in the presence of the phase-forming components, on the phase diagrams of different classes of ATPMS. In addition, we evaluated how different LPS loads affect the GFP partitioning in ATPMS, and a comparative evaluation of the best systems (PEG/NaPA + salt-based ATPS vs. $\mathrm{C}_{10} \mathrm{E}_{4}$ /buffer + salt-based ATPMS) was included, and their ability to recover GFP and remove LPS directly from $E$. coli cell lysate was studied in depth. This has been published as Part II of this work, entitled: "Effect of electrolytes as adjuvants in GFP and LPS partitioning in aqueous two-phase systems: 2. Nonionic micellar systems".

\section{Conclusions}

The influence of different electrolytes in promoting the formation of the PEG/NaPA ATPS at $25^{\circ} \mathrm{C}$ was studied. We concluded that $\mathrm{Li}_{2} \mathrm{SO}_{4}$ and $\mathrm{NaCl}$ are more effective than $\mathrm{KNO}_{3}$ and $\mathrm{KI}$ in promoting the formation of a demixing region. The highest influence was obtained at a high electrolyte concentration $(0.25 \mathrm{M})$ because the entropy of mixing of the counterions in the PEG/NaPA ATPS is decreased.

GFP remained stable after $24 \mathrm{~h}$ at $25^{\circ} \mathrm{C}$ in the presence of all ATPS components. All the partitioning studies showed that GFP and LPS partition preferentially to the top (PEG-rich) phase, demonstrating that hydrophobic and electrostatic interactions are the major driving forces for partitioning. The $K_{\mathrm{GFP}}$ values were more pronounced in the presence of $0.25 \mathrm{M} \mathrm{Li}_{2} \mathrm{SO}_{4}$ and $\mathrm{NaCl}\left(K_{\mathrm{GFP}, \mathrm{Li} 2 \mathrm{SO} 4}>K_{\mathrm{GFP}, \mathrm{NaCl}}\right)$ when compared with other salts tested $\left(K_{\mathrm{GFP}, \mathrm{KNO}} \approx K_{\mathrm{GFP}, \mathrm{KI}}\right)$. The presence of different loads of LPS influenced the GFP partitioning, in which $K_{\mathrm{GFP}}$ without 
LPS $>K_{\mathrm{GFP}}$ with $10^{4} \mathrm{EU} / \mathrm{mL}$ LPS $>K_{\mathrm{GFP}}$ with $10^{6} \mathrm{EU} / \mathrm{mL}$ LPS. A partitioning coefficient of GFP from cell lysate of 20.2 was obtained with $12 \mathrm{wt} \%$ PEG/12 $\mathrm{wt} \% \mathrm{NaPA}+0.25 \mathrm{M} \mathrm{Li}_{2} \mathrm{SO}_{4}$. At the same time, the GFP purification factor in terms of total proteins was increased 4fold.

The results obtained in this work indicate that a proper design of the ATPS platform is fundamental for the purification of proteins from $E$. coli cell lysate. Although ATPS is effective for target-protein recovery and purification (relative to the protein contaminants), the inability to reduce LPS to acceptable levels is still a drawback. A possible method to improve LPS removal is the use of an additional ATPS step based on affinity interactions. Nonetheless, the PEG/NaPA + electrolyte ATPS shows potential for the recovery of the target biomolecule, and thus can be considered an alternative low-cost (low polymer and salt content) and ecologically friendly (mild conditions) downstream processing platform.

\section{Acknowledgements}

The authors are grateful for financial support from FAPESP (São Paulo Research Foundation, Brazil) through the following projects: 2005/60159-7; 2007/51978-0; 2014/16424-7; and 2014/19793-3. The authors also acknowledge the support from CAPES (Coordenação de Aperfeiçoamento de Pessoal de Nível Superior, Brazil) through the process \#0366/09-9 and CNPq (Conselho Nacional de Desenvolvimento Científico e Tecnológico, Brazil).

\section{Appendix A. Supplementary data}

Supplementary data associated with this article can be found, in the online version, at https://doi.org/10.1016/j.seppur.2018.04.090.

\section{References}

[1] J. Kim, S.I. Kim, E. Hong, Y. Ryu, Strategies for increasing heterologous expression of a thermostable esterase from Archaeoglobus fulgidus in Escherichia coli, Prot. Express Purif. 127 (2016) 98-104.

[2] F.A. Falchi, E.A. Maccagni, S. Puccio, C. Peano, C. De Castro, A. Palmigiano, D. Garozzo, A.M. Martorana, A. Polissi, G. Dehò, P. Sperandeo, Mutation and suppressor analysis of the essential lipopolysaccharide transport protein LptA reveals strategies to overcome severe outer membrane permeability defects in Escherichia coli, J. Bacteriol, 200 (2018) e00487-e517.

[3] A.Y. Gyurova, S.V. Stoyanov, E. Mileva, Capture of LPS traces in aqueous solutions by tectomers of four-antennary oligoglycines, Colloid Surf. A 520 (2017) 914-921.

[4] M. Daneshian, A. Guenther, A. Wendel, T. Hartung, S. von Aulock, In vitro pyrogen test for toxic or immunomodulatory drugs, J. Immunol. Methods 313 (2006) $169-175$.

[5] B. Szermer-Olearnik, J. Boratyński, Removal of endotoxins from bacteriophage preparations by extraction with organic solvents, PLoS One 10 (2015) e0122672.

[6] P.O. Magalhães, A.M. Lopes, P.G. Mazzola, C.O. Rangel-Yagui, T.C. Penna, A. Pessoa Jr, Methods of endotoxin removal from biological preparations: a review, J. Pharm. Pharm. Sci. 10 (2007) 388-404.

[7] A. Bergstrand, C. Svanberg, M. Langton, M. Nyden, Aggregation behavior and size of lipopolysaccharide from Escherichia coli O55:B5, Colloids Surf. B 53 (2006) 9-14.

[8] W. Richter, V. Vogel, J. Howe, F. Steiniger, A. Brauser, M.H. Koch, M. Roessle, T. Gutsmann, P. Garidel, W. Mäntele, K. Brandenburg, Morphology, size distribution, and aggregate structure of lipopolysaccharide and lipid A dispersions from enterobacterial origin, Innate Immun. 17 (2010) 427-438.

[9] N. de Mas, D.C. Kientzler, D. Kleindienst, Endotoxin removal from a small-molecule aqueous drug substance using ultrafiltration: a case study, Org. Process Res. Dev. 19 (2015) 1293-1298.

[10] K.L. Williams, Endotoxins: Pyrogens, LAL Testing and Depyrogenation, third ed., CRC Press, 2007.

[11] T.M. Buetler, H. Latado, E. Leclerc, B. Weigle, A. Baumeyer, C.W. Heizmann, G. Scholz, Glycolaldehyde-modified $\beta$-lactoglobulin AGEs are unable to stimulate inflammatory signaling pathways in RAGE-expressing human cell lines, Mol. Nutr. Food Res. 55 (2011) 291-299.

[12] M. Teodorowicz, O. Perdijk, I. Verhoek, C. Govers, H.F. Savelkoul, Y. Tang, H. Wichers, K. Broersen, Optimized Triton X-114 assisted lipopolysaccharide (LPS) removal method reveals the immunomodulatory effect of food proteins, PloS one 12 (2017) e0173778.

[13] A.M. Azevedo, P.A.J. Rosa, I.F. Ferreira, M.R. Aires-Barros, Chromatography-free recovery of biopharmaceuticals through aqueous two-phase processing, Trend Biotechnol. 27 (2009) 240-247.

[14] S.C. Lo, R.N. Ramanan, B.T. Tey, W.S. Tan, P.L. Show, T.C. Ling, C.W. Ooi,
Purification of the recombinant enhanced green fluorescent protein from Escherichia coli using alcohol + salt aqueous two-phase systems, Sep. Purif. Technol. 192 (2018) 130-139.

[15] J.V. Molino, A.M. Lopes, D.A.V. Marques, P.G. Mazzola, J.L. Silva, M.H. Hirata, R.D.C. Hirata, M.S.V. Gatti, A. Pessoa Jr, Application of aqueous two-phase micellar system to improve extraction of adenoviral particles from cell lysate, Biotechnol. Appl. Biochem. (2017), http://dx.doi.org/10.1002/bab.1627.

[16] P.A.J. Rosa, A.M. Azevedo, I.F. Ferreira, S. Sommerfeld, W. Backer, M.R. AiresBarros, Downstream processing of antibodies: single-stage versus multi-stage aqueous two-phase extraction, J. Chromatogr. A 1216 (2009) 8741-8749.

[17] P.A.J. Rosa, I.F. Ferreira, A.M. Azevedo, M.R. Aires-Barros, Aqueous two-phase systems: a viable platform in the manufacturing of biopharmaceuticals, J. Chromatogr. A 1217 (2010) 2296-2305.

[18] P.A.J. Rosa, A.M. Azevedo, S. Sommerfeld, W. Backer, M.R. Aires-Barros, Aqueous two-phase extraction as a platform in the biomanufacturing industry: economical and environmental sustainability, Biotechnol. Adv. 29 (2011) 559-567.

[19] F.A. Vicente, L.P. Malpiedi, F.A. Silva, A. Pessoa Jr., J.A.P. Coutinho, S.P.M. Ventura, Design of novel aqueous micellar two-phase system using ionic liquids as co-surfactants for the selective extraction of (bio)molecules, Sep. Purif. Technol. 135 (2014) 259-267.

[20] M.G. Freire, A.F.M. Cláudio, J.M.M. Araújo, J.A.P. Coutinho, I.M. Marrucho, J.N.C. Lopes, L.P. Rebelo, Aqueous biphasic systems: a boost brought about by using ionic liquids, Chem. Soc. Rev. 41 (2012) 4966-4995.

[21] P.G. Mazzola, A.M. Lopes, F.A. Hasmann, A.F. Jozala, T.C. Penna, P.O. Magalhaes, C.O. Rangel-Yagui, A. Pessoa Jr, Liquid-liquid extraction of biomolecules: an overview and update of the main techniques, J. Chem. Technol. Biot. 83 (2008) $143-157$.

[22] J.V. Molino, V. Marques, D. Araújo, A. Pessoa Jr, P.G. Mazzola, M.S. Gatti, Different types of aqueous two-phase systems for biomolecule and bioparticle extraction and purification, Biotechnol. Progr. 29 (2013) 1343-1353.

[23] R.R. Soares, A.M. Azevedo, J.M. Van Alstine, M.R. Aires-Barros, Partitioning in aqueous two-phase systems: analysis of strengths, weaknesses, opportunities and threats, Biotechnol. J. 10 (2015) 1158-1169.

[24] A.M. Lopes, P.O. Magalhaes, P.G. Mazzola, C.O. Rangel-Yagui, T.C.V. Penna, A. Pessoa Jr, LPS removal from an E. coli fermentation broth using aqueous twophase micellar system, Biotechnol. Progr. 26 (2010) 1644-1653.

[25] A.M. Lopes, P.O. Magalhaes, P.G. Mazzola, C.O. Rangel-Yagui, J.C.M. Carvalho, T.C.V. Penna, A. Pessoa Jr, Green fluorescent protein extraction and LPS removal from $E$. coli fermentation medium using aqueous two-phase micellar system, Sep. Purif. Technol. 81 (2011) 339-346.

[26] A.M. Lopes, V.C. Santos-Ebinuma, L.C.L. Novaes, J.V. Molino, L.R.S. Barbosa, A. Pessoa Jr, C.O. Rangel-Yagui, LPS-protein aggregation influences protein partitioning in aqueous two-phase micellar systems, Appl. Microbiol. Biot. 97 (2013) 6201-6209.

[27] Y. Aida, M.J. Pabst, Removal of endotoxin from protein solutions by phase separation using Triton X-114, J. Immunol. Methods 132 (1990) 191-195.

[28] J. Boratyński, B. Szermer-Olearnik, Endotoxin removal from Escherichia coli bacterial lysate using a biphasic liquid system, in: O. Holst (Eds), Microbial Toxins, Methods in Molecular Biology, vol. 1600, Humana Press, New York, 2017, pp. $107-112$.

[29] P. Reichelt, C. Schwarz, M. Donzeau, Single step protocol to purify recombinant proteins with low endotoxin contents, Prot. Express Purif. 46 (2006) 483-488.

[30] V. Gupta, S. Nath, S. Chand, Role of water structure on phase separation in polyelectrolyte-polyethyleneglycol based aqueous two-phase systems, Polymer 43 (2002) 3387-3390.

[31] H.O. Johansson, M. Ishii, M. Minaguti, E. Feitosa, T.C. Penna, A. Pessoa Jr, Separation and partitioning of green fluorescent protein from Escherichia coli homogenate in poly (ethylene glycol)/sodium-poly (acrylate) aqueous two-phase systems, Sep. Purif. Technol. 62 (2008) 166-174.

[32] H.O. Johansson, E. Feitosa, A. Pessoa Jr, Phase diagrams of the aqueous two-phase systems of poly (ethylene glycol)/sodium polyacrylate/salts, Polymers 3 (2011) 587-601.

[33] S. Saravanan, J.R. Rao, B.U. Nair, T. Ramasami, Aqueous two-phase poly(ethylene glycol)-poly(acrylic acid) system for protein partitioning: influence of molecular weight, pH and temperature, Process Biochem. 43 (2008) 905-911.

[34] X. Zhao, X. Xie, Y. Yan, Liquid-liquid equilibrium of aqueous two-phase systems containing poly (propylene glycol) and salt $\left(\left(\mathrm{NH}_{4}\right)_{2} \mathrm{SO}_{4}, \mathrm{MgSO}_{4}, \mathrm{KCl}\right.$, and $\left.\mathrm{KAc}\right)$ : experiment and correlation, Thermochim. Acta 516 (2011) 46-51.

[35] T.C.V. Penna, E. Chiarini, A. Pessoa Jr., Permeation associated with three phase partitioning method on the release of green fluorescent protein (GFPuv) from Escherichia coli, Appl. Biochem. Biotechnol. 105 (2003) 481-491.

[36] O. Westphal, K. Jann, Bacterial lipopolysaccharides: extraction with phenol-water and further applications of the procedure, Methods Carbohydr. Chem. 5 (1965) 83-91.

[37] US Pharmacopeia and National Formulary-USP-24-NF-19, Bacterial endotoxins, Test (Suppl. 85) (2000) 2875-2879.

[38] S. Sokalingam, G. Raghunathan, N. Soundrarajan, S.G. Lee, A study on the effect of surface lysine to arginine mutagenesis on protein stability and structure using green fluorescent protein, PLoS One 7 (2012) e40410.

[39] W.W. Ward, [Chapter 3], Gre En Fluorescent Protein: Properties, Applications and Protocols, John Wiley \& Sons, 2005, pp. 39-65.

[40] M. Ishii, J.S. Kunimura, O. Cholewa, T.C.V. Penna, Study on the termal stability of Green Fluorescent Protein (GFP) in glucose parenteral formulations, Int. J. Pharm. 337 (2007) 109-117.

[41] S.S. Sabo, A.M. Lopes, V.C. Santos-Ebinuma, C.O. Rangel-Yagui, R.P.S. Oliveira, Bacteriocin partitioning from a clarified fermentation broth of Lactobacillus 
plantarum ST16Pa in aqueous two-phase systems with sodium sulfate and cholinebased salts as additives, Process Biochem. 66 (2018) 212-221.

[42] J.F.B. Pereira, V.C. Santos, H.O. Johansson, J.A.C. Teixeira, A. Pessoa-Junior, A stable liquid-liquid extraction system for clavulanic acid using polymer-based aqueous two-phase systems, Sep. Purif. Technol. 98 (2012) 441-450.

[43] M. Noel, D. Combes, Rhizomucor miehei lipase: differential scanning calorimetry and pressure/temperature stability studies in presence of soluble additives, Enzyme Microb. Technol. 33 (2003) 299-308.

[44] T. Kurinomaru, K. Shiraki, Noncovalent PEGylation of L-Asparaginase using PEGylated polyelectrolyte, J. Pharm. Sci. 104 (2015) 587-592.

[45] L.C. de Lencastre Novaes, P.G. Mazzola, A. Pessoa-Jr, T.C. Penna, Effect of polyethylene glycol on the thermal stability of green fluorescent protein, Biotechnol. Progr. 26 (2010) 252-256.

[46] L. Piculell, B. Lindman, Association and segregation in aqueous polymer/polymer, polymer/surfactant, and surfactant/surfactant mixtures: similarities and differences, Adv. Colloid Interface 41 (1992) 149-178.

[47] G. Johansson, Effects of salts on the partition of proteins in aqueous polymeric biphasic systems, Acta Chem. Scand. B 28 (1974) 873-882.

[48] Y. Marcus, Effect of ions on the structure of water: structure making and breaking, Chem. Rev. 109 (2009) 1346-1370.

[49] Y. Marcus, A simple empirical model describing the thermodynamics of hydration of ions of widely varying charges, sizes, and shapes, Biophys. Chem. 51 (1994)
$111-127$.

[50] V.C. Santos-Ebinuma, A.M. Lopes, A. Pessoa-Jr, M.F. Teixeira, Extraction of natural red colorants from the fermented broth of Penicillium purpurogenum using aqueous two-phase polymer systems, Biotechnol. Progr. 31 (2015) 1295-1304.

[51] D.P. Silva, M.Z. Pontes, M.A. Souza, M. Vitolo, J.B. Almeida Silva, A. Pessoa Jr. Influence of $\mathrm{pH}$ on the partition of glucose-6-phosphate dehydrogenase and hexokinase in aqueous two-phase system, Braz. J. Microbiol. 33 (2002) 196-201.

[52] H.O. Johansson, F.M. Magaldi, E. Feitosa, A. Pessoa-Jr, Protein partitioning in poly (ethylene glycol)/sodium polyacrylate aqueous two-phase systems, J. Chromatogr. A 1178 (2008) 145-153.

[53] F. Hofmeister, Zur lehre von der wirkung der salze. II. Archiv für experimentelle Pathologie und Pharmakologie, 24 (1888) 247-260 (Translated In: W. Kunz, J. Henle, B.W. Ninham, About the Science of the Effect of Salts: Franz Hofmeister's Historical Papers, Curr. Opin. Colloid In. 9 (2004) 19-37).

[54] G. Karlström, On the effective interaction between an ion and a hydrophobic particle in polar solvents. A step towards an understanding of the Hofmeister effect? Phys. Chem. Chem. Phys. 5 (2003) 3238-3246.

[55] E.C. Dullah, C.M. Ongkudon, Current trends in endotoxin detection and analysis of endotoxin-protein interactions, Crit. Rev. Biotechnol. 37 (2017) 251-261.

[56] A. Yuan, R.L. Pardy, C.P. Chia, Nonspecific interactions alter lipopolysaccharide patterns and protein mobility on sodium dodecyl sulfate polyacrylamide gels, Electrophoresis 20 (1999) 1946-1949. 